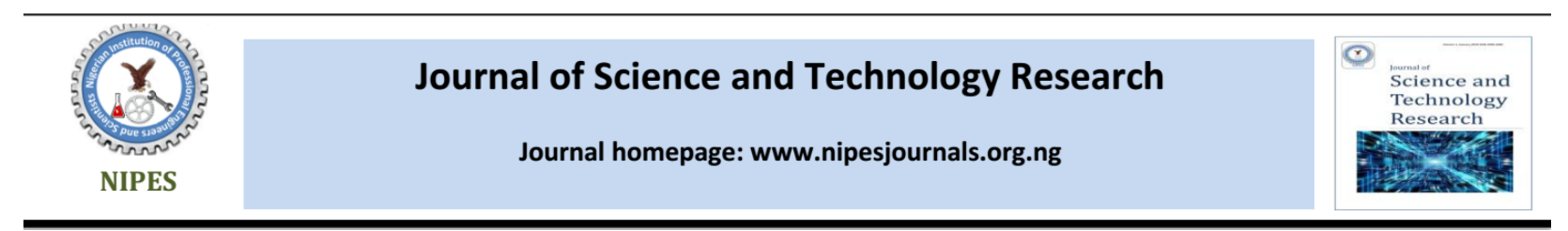

\title{
Development of an Automatic Rain and Voice Activated Vehicle Windscreen Wiper
}

\author{
Hassan A. B..$^{*}$, Abdulmalik D.M. ${ }^{2}$, Yusuf M.A ${ }^{3}$, Garba A.B ${ }^{4}$ \\ ${ }^{13}{ }^{4}$ Department of Mechanical Engineering, Federal University of Technology, P.M.B.65, Minna, Niger State, Nigeria. \\ ${ }^{2}$ Department of Computer Science, Federal University of Technology, P.M.B.65, Minna, Niger State, Nigeria. \\ *Corresponding author email: abhassan@futminna.edu.ng, drmalik@futminna.edu.ng, +2348034529014
}

\begin{tabular}{l} 
Article Info \\
\hline Keywords: \\
Automatic, rain, voice, vehicle, \\
windscreen, wiper \\
\hline Article history: \\
Received 26 February 2020 \\
Revised 16 March 2020 \\
Accepted 20 March 2020 \\
Available online 01 June 2020 \\
C Crossref
\end{tabular}

https://doi.org/10.37933/nipes/2.2.2020.21

https://nipesjournals.org.ng ISSN-2682-5821/@ 2020 NIPES Pub. All rights reserved.

\begin{abstract}
The driver behind the steering is often been confronted with a lot of distractions and disturbances which could be both within the vehicle such as auxiliaries, multimedia features, and safety facilities and outside the vehicle such as weather conditions and other road users. All of these will have the potential of diverting the driver's concentration and may lead to accidents. In view of this, automobile makers are continuously researching for new and innovative ways of making driving stress-free, fascinating and enjoyable for users. One of the focus features that is constantly researched for, is the windscreen wiper. Hence, in this paper, a control circuit for windscreen wiper motor is proposed. The wiper motor is automatically activated by voice or by the presence of water on a sensor causing the wiper blade to sweep back and forth at a speed depending on the intensity of water falling on the windscreen. The development of this automatic wiper system will enhance the comfort and convenience level of drivers behind the steering when it comes to wiper operation especially during rainfall.
\end{abstract}

\section{Introduction}

The windscreen wiper is a very important component of a vehicle that is used to clear rain water or any water from vehicle windscreen. It is important because it makes driving in the rain a possibility and as well reduces the danger involved. In most countries of the world there are provisions for legal requirements which make it compulsory for every automobile to be equipped with windscreen wipers. In Nigeria, vehicle windscreen wipers are one of the important required safety facilities that 'Vehicle Inspection Agencies' look out for during routine automobile safety inspections. The wiper consists of an arm, pivoting at one end and with a long rubber blade attached to the other end. The blade oscillates back and forth over the vehicle windscreen, clearing water from its surface. The wiper has gone through various stages of development and enhancement since its first invention. The speed of the wiper by design can usually be adjusted. Very many vehicles are equipped with two synchronized radial type arms of wipers. In order to be able to produce the great deal of force needed to move the wiper blade over the windscreen at the desired speed, a worm gear is incorporated on the output of a small electric motor. The worm gear reduction is able to increase the torque of the motor by about fifty times, and at the same time reduce the output speed of the electric motor by the same value. The output of the gear reduction is made to operate a linkage that moves the wipers back and forth over the windscreen [9]

In recent past, automakers have tried to either eliminate the wipers or to control their speed automatically. Some of the schemes involved detecting the vibrations caused by individual 
raindrops hitting the windshield, applying special coatings that did not allow drops to form, or even ultrasonically vibrating the windshield to break up the droplets so they don't need to be wiped at all. However, these systems were plagued by problems and either never made it to production or were quickly axed because they annoyed more drivers than they pleased.

Several works have gone into making driving more comfortable, tension-free and safe for the driver. Many efforts have been on at developing more effective, reliable, and cheap automatic rain activated wiper control system for vehicles [2]. A perfect system could subtract one more task from the drivers' workload, and allow them to better keep their eyes on the road and hands on the wheel during rainy period. Despite this, automatic rain activating wiper systems are relatively uncommon in modern vehicles due to cost and unreliability. While a number of different design approaches have been made to improve upon these issues, none have been successful enough for the technology to become widely adapted in new vehicles [12].

These days, many intelligent transportation systems (ITS) have been implemented on vehicles which increase the safety and help to minimize the accident possibility factor. Intelligent vehicle uses various intelligent sensing and control algorithms to assess the vehicle's environment and provide safety to the driver and the passenger. Thus, the development of the automotive intelligent system becomes one of the famous research areas around the globe. Since 1980's researchers are motivated to do the research on the automatic windscreen wiper system. Most of the researches are interested with the sensor and some of it deals with the control algorithm. However, most of the rain sensors invented are really complex and some of it is not very practical to implement to the car [11]. This particular wiper system is design to reduce cost and enhance the workability of an automatic wiper system. The concept of this automatic wiper system is the application of the conductive nature of water in the sensing device used, and the innovative component incorporated in our design is the voice activation command. The features of this automatic windshield wiper are as follows:

i. Self-activation, whenever it rains.

ii. Adjust its speed according to the degree of rainfall: such as drizzle, light or heavy rainfall.

iii. Goes off when not needed.

iv. And, comes on when voice command is activated.

\section{Methodology}

This wiper system has been developed as a prototype to demonstrate the possibility of using a rain sensor (conductive) and a human voice as control switches for the wipers of automobile windscreen. The conductive sensor is used for this wiper system because it is comparatively easier to design and the human voice is also employed to mitigate the drawback that may arise to the system during the cause of usage. The block diagram in Figure 1 describes the design and operation of the system.

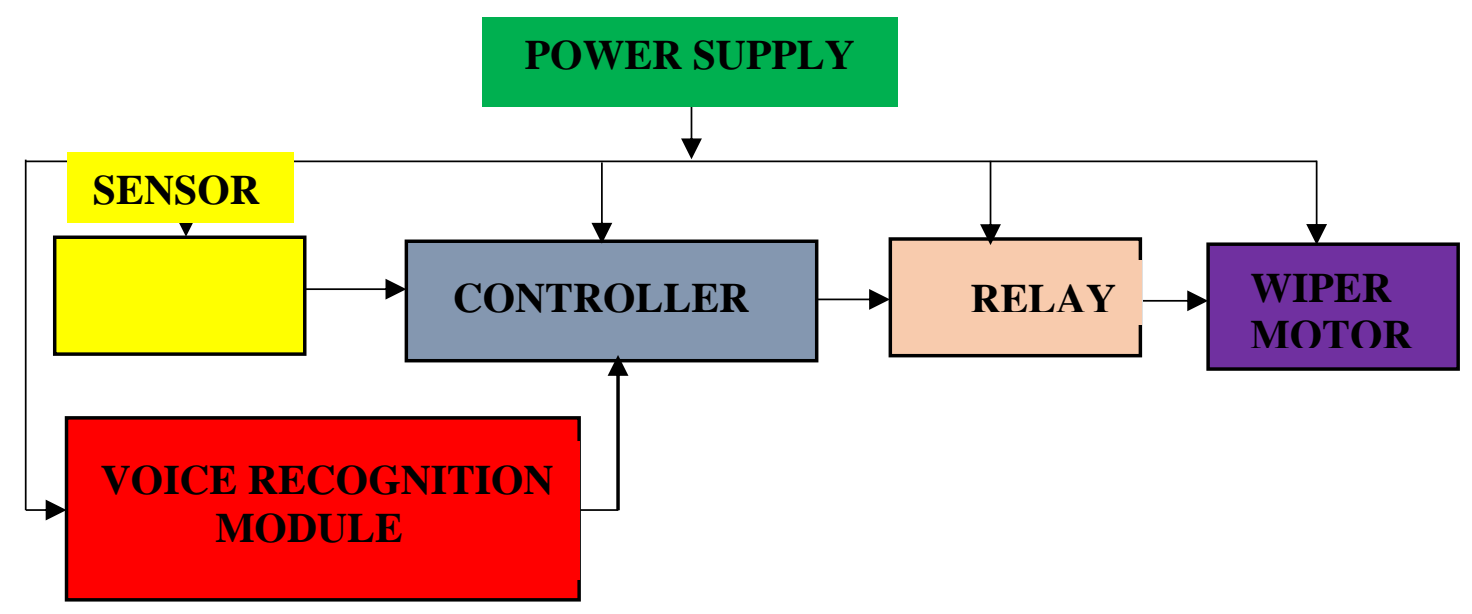

Figure1: Block Diagram of the System 


\subsection{Components and Material Selection for the Project}

The materials for this design are in two parts: hardware and software components. The hardware component comprises of mechanical and electronic components, while the software is made of C Programming language and Accessport software for the voice training of the voice recognition module. The hardware components used for this research and their specification are presented in Table 1.

Table 1: Hardware components and their specification

\begin{tabular}{ccc}
\hline S/N & Material & Specification \\
\hline 1 & A wiper motor & \\
2 & Wiper Blade & \\
3 & Glass frame & \\
4 & Supporting Structure- aluminum metal/frame & \\
5 & Metallic Stand & diameter (15mm \\
6 & Plastic Bucket & Pour (AH) \\
7 & Rubber Hose & PIC16f628 \\
8 & Battery & \\
9 & PIC Micro Controller & \\
10 & Conductive Sensor & \\
11 & Relay & \\
12 & Variable Voltage Regulator & \\
14 & Transistor & \\
\hline
\end{tabular}

\subsubsection{The Wiper Motor}

The DC motor used to drive the wiper is a WM45F model three-speed wiper motor. The motor is selected to suit our power source and to carry the wiper blade. It makes use of a voltage of $12 \mathrm{~V}$ supplied by a dry cell battery. The output of the wiper motor is connected to linkages to actuate the wiper blade. It draws a current of 1.6A when there is no load on it and it has a speed of 70 RPM.

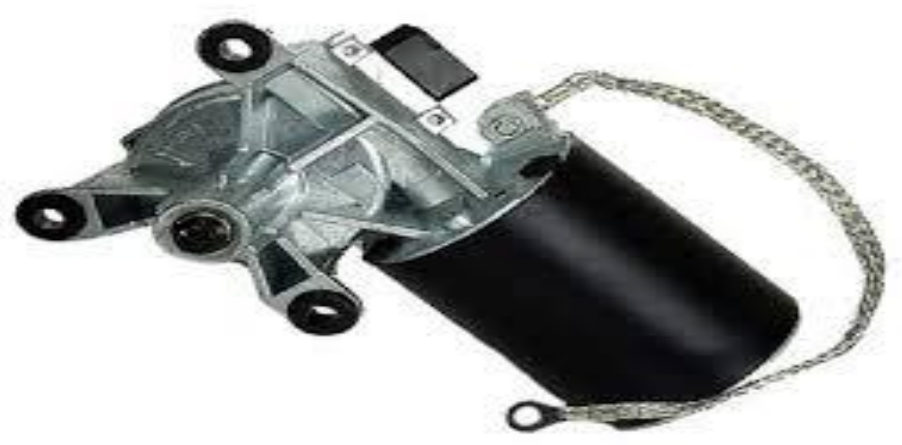

Figure 2: DC Wiper Motor

\subsubsection{Selection of Conductive Rain Sensor}

The conductive Rain Sensor is designed to operate on the principle of conduction of electric current. The sensor probes placed inside a trough (control volume) which is positioned at the bottom of the windscreen is used to detect the quantity of rain water falling on the windscreen. These sensors send data to the microcontroller depending on the level of water collected in the trough, which in turn measures the rain intensity to activate the wiper and adjust its speed accordingly. This process involved the use of a comparator chip - Linear Monolithic (LM) 324 - which contains four comparators within it. 


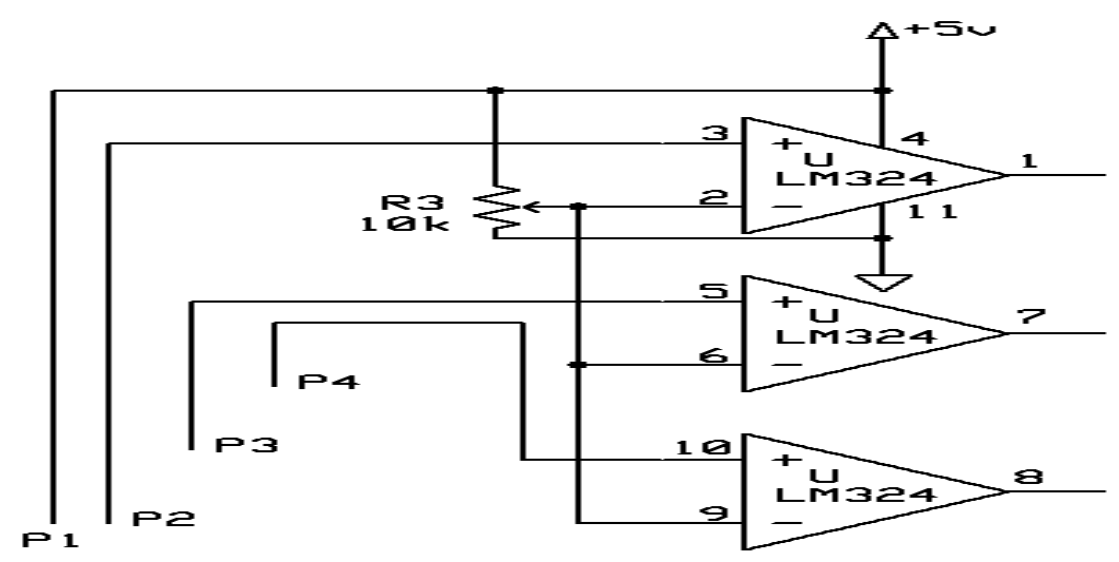

Figure 3: Circuit diagram of Conductive Rain Sensor

\subsubsection{Selection of the PIC Micro Controller - PIC16f628A}

The PIC16f628A Micro controller is the brain of this wiper system. It is selected for its low cost, coupled with its versatility and performance in logical operations as well as its adaptable communication with other electronic devices. The micro controller is programmed in such a way to analyze the input from the sensor and varies the speed of the wiper depending on the intensity of rainfall. The basic circuit diagram of the controller is shown in Figure 4.

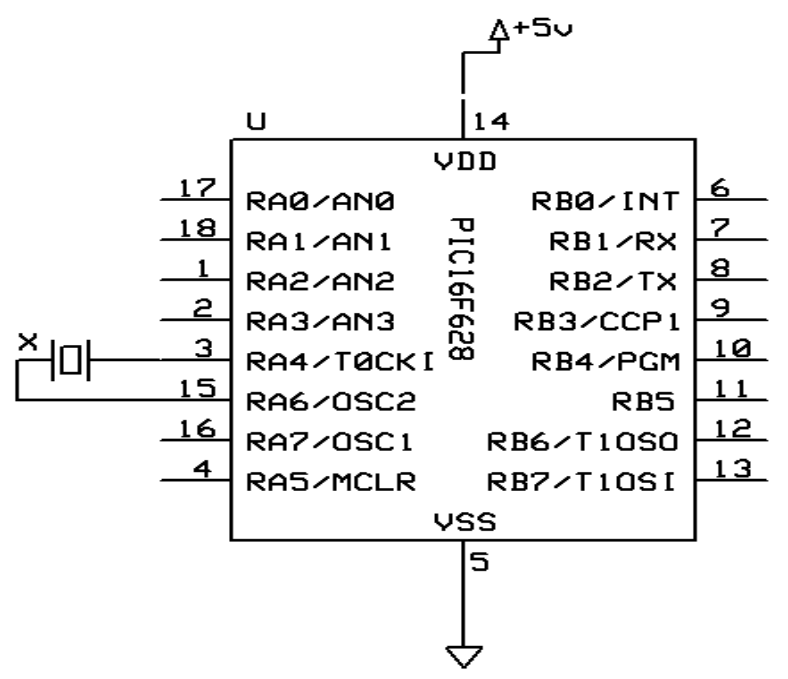

Figure 4: Circuit Diagram of the Controller

\subsubsection{Selection of the Relay}

"A relay is a switch, which works with the help of an electromagnet", (Ashik and Basavaraju 2014). The relay is used as an amplifier. The $12 \mathrm{~V}$ current in the circuit is used by the relay to control the motor circuit, which drives the wiper motor. This is made possible with the use of electromagnetic switch as shown in Figure 5. 


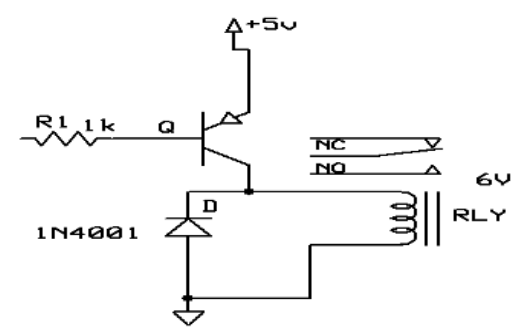

Figure 5: The Circuit Diagram of the Relay

\subsubsection{Selection of the Transistor}

The output of microcontroller circuit is $5 \mathrm{~V}$ only. By having this $5 \mathrm{~V}$, it is not possible to drive the relay and DC motor. So the driver circuit is used to increase the output signal from $5 \mathrm{~V}$ to $12 \mathrm{~V}$. This $12 \mathrm{~V}$ is enough to operate the relay and wiper motor. The transistor used is A1015 biased with a $1 \mathrm{~K}$ ohms resistor.

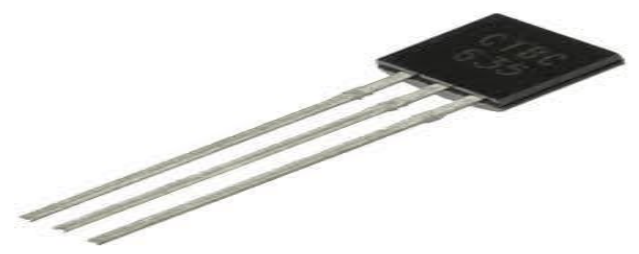

Figure6: Picture of Transistor

\subsubsection{Selection of Power Source}

The power supply is provided by the use of a $12 \mathrm{~V} 7.5 \mathrm{AH}$ Panasonic dry cell battery. It is selected because of its compact nature; ability to be able to store power for a considerable length of time and also get recharged once the power has been used up.

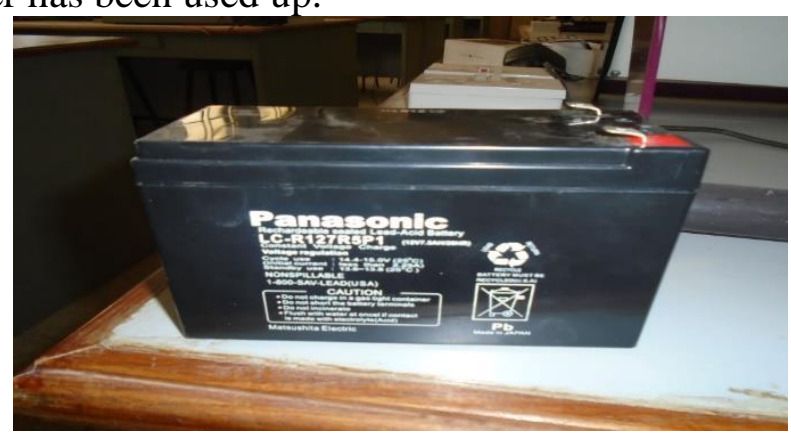

Figure 7: Picture of Dry Cell Battery

\subsubsection{Selection of the Voltage Regulator}

Regulator is an electronic circuit whose function is to keep the output always constant, though the input is varied. The voltage regulator (7805 series) was used to maintain $5 \mathrm{~V}$ supply to the microcontroller, since the microcontroller and the voice module cannot support power with more than $5 \mathrm{~V}$. The circuit diagram of these regulators is shown in Figure 3.7.

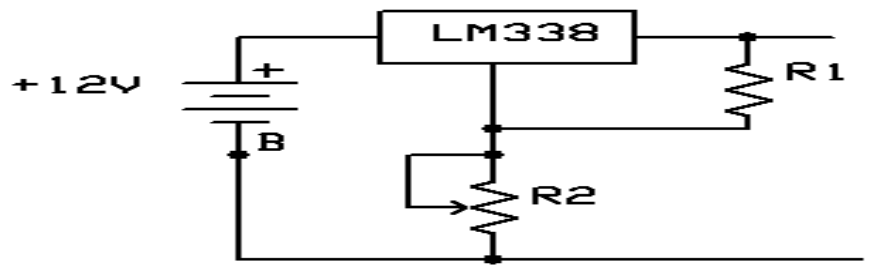

Figure 7: Circuit Diagram of Variable Voltage Regulator 


\subsubsection{The Selection Voice Recognition Module}

This is a device used for speech-controlled system because it recognizes speeches. The system which has to be trained by the use of serial port, needed a Universal Serial Bus (USB) to Universal Synchronous/Asynchronous Receiver/Transmitter (USART) converter. The pictorial views are shown in Figure 8 and 9.

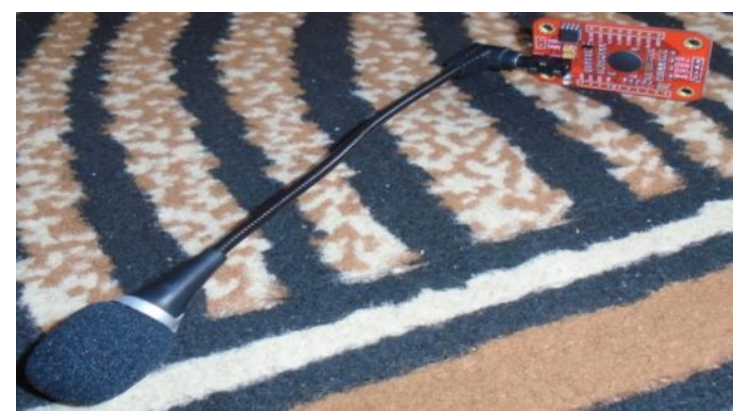

Figure 8: Pictorial view of the Voice Recognition Module

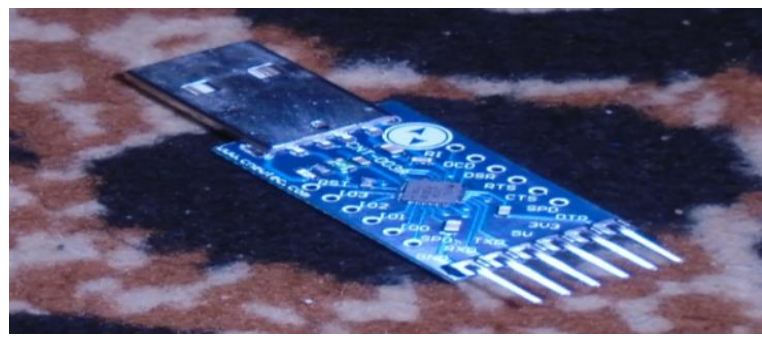

Figure 9: Picture of the USB to USART converter

To train the voice recognition module, one has to connect the USB-to-USART converter to a Personal Computer (PC), and then connect the voltage input ( $\mathrm{Vcc}$ ) of the converter to the voltage input (Vcc) of the voice module, also their ground pins must be appropriately link together too. After these steps have been undertaken, a software called Accessport was used to do the speech training. The interface of the software is shown in the figure 10.

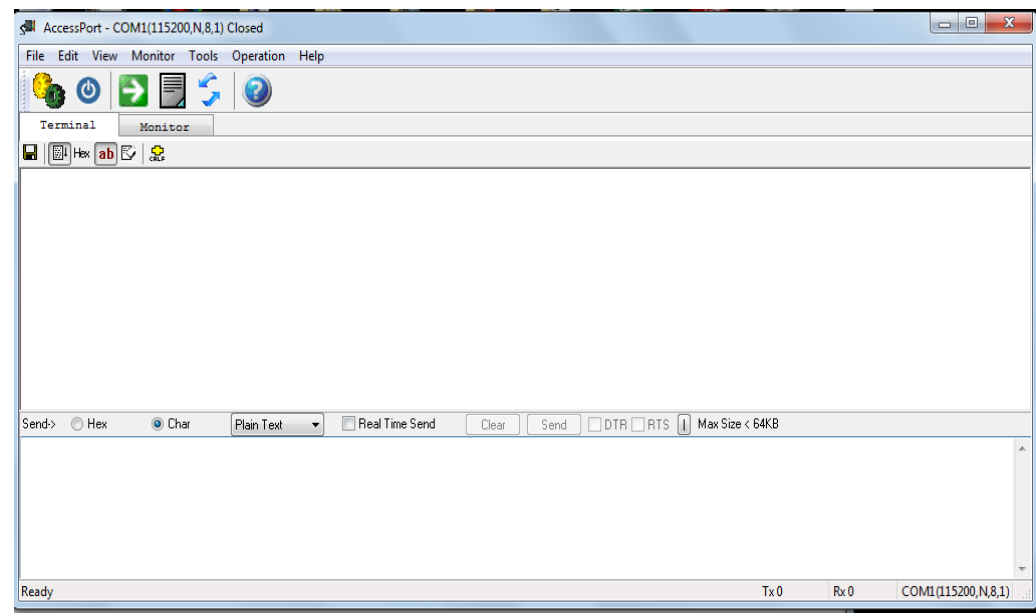

Figure 10: Access port software Interface. 


\subsection{Design Analysis for the Wiper System}

In the design analysis, the focus is on the control for the Automatic Rain Activated wiper by designing an appropriate capacity of the water trough, the length of the probe sensors, the radius of the sink to drain the rain water and the transmission angle of wiper.

\subsubsection{Design Analysis of the Control Volume (Trough)}

The Capacity of control trough, $\mathrm{V}_{\mathrm{T}}=l \times b \times a$

Where:

$l=$ Length of control trough

$b=$ Breadth of control trough

$a=$ depth of control trough

\subsubsection{Design Analysis for the Length of the Sensor}

The lengths of Sensors $S_{n}$ is given as follows:

$$
\mathrm{S}_{\mathrm{n}}=a-\frac{\mathrm{Q}}{l b} \mathrm{~T}_{\mathrm{n}}
$$

Where:

$$
\begin{aligned}
& \mathrm{Q}=\text { Volume lapse rate } \\
& \mathrm{T}=\text { Time } \\
& a=\text { depth of control trough }
\end{aligned}
$$

\subsubsection{Design Analysis for the Diameter of the Control Sink}

For the design analysis of the control sink, the equation for the strength of a sink and that of volume lapse rate were employed to design the diameter of the sink.

Strength of a sink is given by:

$$
\varphi=\pi D u
$$

Where, $D=$ Diameter of sink

$u=$ Velocity of water

Volume lapse rate is given by, $\mathrm{Q}_{\mathrm{F}}=\frac{\text { Volume of trough }}{\text { Total Time }}$

$$
\mathrm{Q}_{\mathrm{F}}=\frac{l \times b \times a}{T}
$$

Equating both equations to get radius, $\pi D u=\frac{l \times b \times a}{T}$

Therefore diameter, $\quad D=\frac{l \times b \times a}{\pi \times u \times T}$

\subsubsection{Design Analysis of Angle of Wipe}

$$
\begin{aligned}
& \emptyset=\cos ^{-1}\left(\frac{2 L^{2}-W^{2}}{2 L^{2}}\right) \\
& \text { Where } \\
& \text { W }=\text { Length of wipe area } \\
& \mathrm{L}=\text { Length of wiper }
\end{aligned}
$$

\subsection{Mode of Operation of the Wiper System}

In this project, the glass is fixed on an aluminum stand. The wiper motor is fixed behind the glass frame, while a separate stand is constructed for the control panel which contains the electronic and software parts. The wiper blade is fixed in front of the glass frame to remove the rain water on the glass frame. The set-up for the system is as shown in figure 11. 


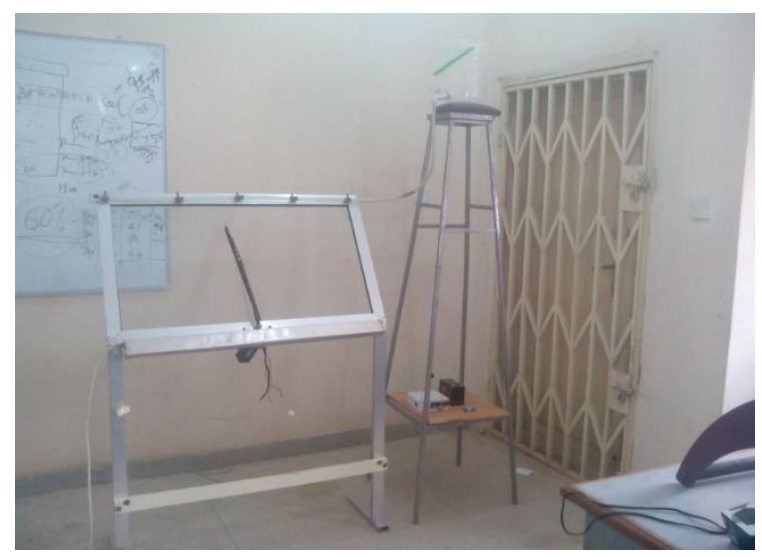

Figure 11: Picture of the Project Set-up

When powered and rain is not falling pins 1,7 and 8 of the comparators will be at logic low (0V). As rain falls the system has a place for water collection with an orifice of escape. If the water is collected this will bridge S1 and S2 to make only pin 1 to be high. The controller reads this and ensures that relay connected to pin 10 of the controller through transistor is energized so that it will conduct power from LM338 with label BB3. The potentiometer of the regulator is set to achieve $10 \mathrm{~V}$, making the motor speed to be at its minimum. As the rain increases, and S1, S2 and S3 are bridged, pins 1 and 7 of the controller are at logic high. The controller sees this and de-energizes the previous relay and energizes the one connected to pin 11 of the controller. This will bring in $11 \mathrm{~V}$ from LM338 with BB2 label to the motor thereby increasing the speed. If it further persists, it will bridge all probes to energize only the relay connected to pin 9 of the controller. At this point it will be at maximum speed since $12 \mathrm{~V}$ from the battery comes in. For the voice switch whenever we speak, there is a disturbance of air particles which comes in the form of vibrations in the air. This vibration is picked up by a very thin diaphragm in the microphone which is connected to the speech recognition module. As the diaphragm moves back and forth, it moves with a coil attached to it. The movement of the coil cuts through a magnetic field produced by a permanent magnet also inside the microphone.

According to Faraday's Law, as the coil moves through the magnetic field, voltage is generated and this is used to power the wiper motor. To prevent the system from responding to any sound the voice recognition module has been used to convert the analog wave into digital data to activate this wiper system. So, by the voice training of the voice recognition module, once the word "ON" is spoken to the microphone, the wiper starts working at medium speed while the word "OFF" is used to stop its operation.

\section{Result and Discussion}

From the design calculation each sensor length is determine from the time desired for the response of the particular sensor. Table 2 shows the results of the relationship between response time and sensor length. 
TABLE 2: Table of the result of the determination of Sensor length from Response time

\begin{tabular}{ccc}
$\begin{array}{c}\text { Serial } \\
\text { Number }\end{array}$ & Response Time (s) & Sensor Length (mm) \\
\hline 1 & 5 & 49.13 \\
2 & 120 & 47.56 \\
3 & 240 & 45.92 \\
\hline
\end{tabular}

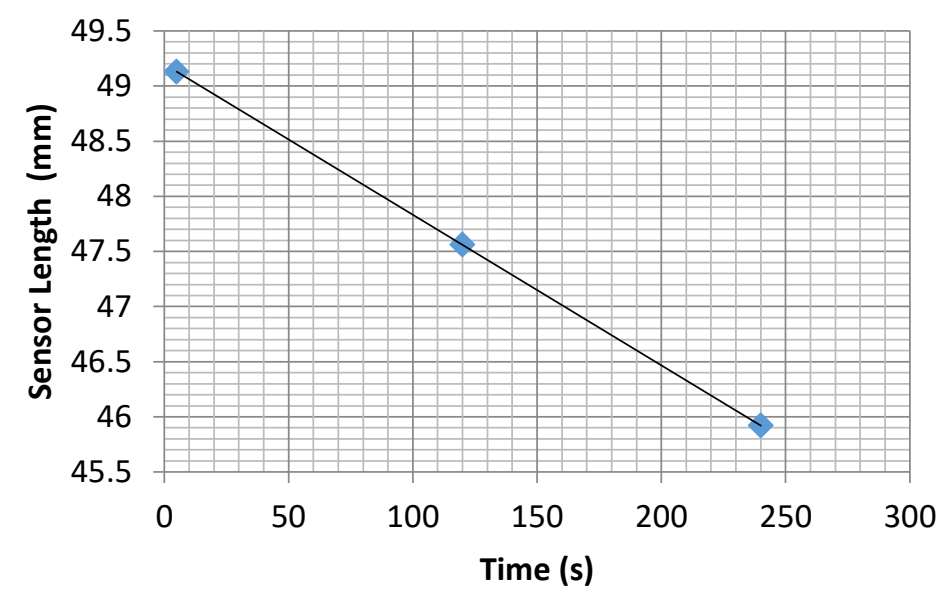

Figure 3.1: Graph showing relationship between sensor length and time

\subsection{The Sensor Response and Operation}

Three sensors were used to detect the level of water in the container for the collection of water. The sensors are placed inside this container. The water flowing from the plastic bucket through the rubber hose to the glass frame is collected in the containers which have been placed at an appropriate position. When the water starts to flow only small quantity of water is collected in the container at that instant of time. At this point the first sensor is kept at the bottom level of the container. The sensors are powered with a voltage of $5 \mathrm{~V}$ from the micro controller. So, when the water collected at the bottom level covers the first sensor, the current pass through the sensor and completes the circuit and as well the wiper motor is powered to actuate the wiper blade to clear the water from the glass frame.

As the water continues to flow, the level of water collected in the trough increased to half its capacity. At this point the second sensor is buried by the water and its conducts current and completes the circuit to switch the wiper to operate at the medium speed. With an increase in the water level in the trough and this reaching the maximum point and the third sensor now buried inside water. This too conducts current and bridges the circuit and the wiper motor is activated to clear the water from the glass frame at the high speed. From the testing, the sensor had been very sensitive and the response rate high. 


\subsection{The Voice Activation Sensitivity}

Whenever it is desire to control the system with the voice command, the button for voice control is first enabled. Once the button is pressed then a red indicator light on the control panel comes on, then the voice module sends a code to the microcontroller via the COM port. The command is received by the system through a microphone voice recognition module acted as a transducer to convert sound energy into electrical energy to power the wiper motor. The first input command which was earlier trained is "ON" while the second input command trained for the system is "OFF". With the voice-switch mode activated and as the first input command that is, "ON", is spoken the wiper starts to work to clean the glass frame. To stop the wiper operation, the second input command ("OFF") was uttered and the wiper motion came to a halt.

When the output is on then the connected Light Emitting Diode (LED) is on and when the output is off then connected LED is off. This system is designed to recognise the voice of the user that will be employed as a control switch for the system, thus this turn out to be an issue during testing of the system. The challenge is to be able to pronounce and repeat the same words used for the training process. The time of response of the system to the voice command was found out to be about five second $(5 \mathrm{sec})$. Since this determines the level of sensitivity of the voice activation mode, therefore it can be concluded that the sensitivity is high and satisfactory.

\section{Conclusion and Recommendations}

\subsection{Conclusion}

This wiper system has been successfully tested and found to be accurate and to some extend sensitive in operation. It is an improvement on the existing wiper control system as well as a modification on other versions of automatic windscreen wiper systems. The conductive sensor was used to accurately detect the presence of rain water and help to activate the wiper motor and also select three varying speeds of wiper operation depending on the intensity of rainfall. In addition, the voice activation has been able to provide an alternative control switch were the presence of water is as result of other conditions such as splash of water on the windscreen by a passing vehicle. This windscreen wiper control system will help to facilitate tension free driving and improve driver's comfort level. It will be an assistance to drivers who had to move at night and in areas known for heavy vehicular traffic, where they have to concentrate on accelerator, brake and or clutch. Shifting the wiper control during rain from the manual mode will afford the drivers much ease and enable them concentrate on basics (Accelerator, Brake and or Clutch) of driving condition.

\subsection{Recommendations}

Though the testing and operation of this wiper control system has been largely successful, there are still aspects of improvement on this project for future scholastic work. In the light of this, the underlisted suggestions for improvement is recommended for further research.

i. $\quad$ Further work can be carried out on a different type of sensor, other than the one used in this wiper system.

ii. The control system could be better enhanced for improve sensitivity in the operation of this wiper system by using a more efficient and adaptable coding system.

iii. The voice control switch employed in this system could be modified to recognize any user's voice and not just a particular trained voice.

iv. Also, the voice control switch can be applied for industrial applications for controlling the industrial appliances and industrial motors.

v. Finally, based on the test performance; the system can be easily applied to the present-day economic class automobiles 


\section{References}

[1] Allen and Bradley, (1996). Motor Fundamentals. Rockwell Automation, page 4

[2] Amir F.B.A. A., (2006). Mara University of Technology, Shah Alam, Selangor, Develop a Rain Sensitive Windscreen Wiper Using PIC 16F84A, pages 13 and 14.

[3] Arthi,J.E. \& Jagadeeswari,M., (2014). Control of Electrical Appliances through Voice Commands, IOSR Journal Electrical and Electronics Engineering (IOSR-JEEE), 1(9), page 13-18, Retrieved on 16th March, 2016 from http://www.iosrjournals.org

[4] Ashik, K.P., \& Basavaraju, A. N., (2014). Automatic Wipers with Mist Control, American Journal of Engineering Research (AJER), 3(4), 24-34. Retrieved on 20th January, 2016 from http://www.ajer.com

[5] Bailey, T., (2005). An Introduction to the C Programming Language and Software Design. Retrieved on 23rd March, 2016 from http://www.wikipedia.com

[6] Beauvais, K., (2003). The Simple DC Motor: A Teacher Guide. Massachusetts Institute of Technology, Page 4. Retrieved on 10th February, 2016 from http://www.wikipedia.com

[7] Hashim, N.M.Z.Husin, S. H., \& Hamid, N.A.A., (2013). Smart Wiper Control System, International Journal of Application or Innovation in Engineering \& Management (IJAIEM), 2(7), 409-415. Retrieved on 19th January, 2016 from http://www.ijaiem.org

[8] Kajioka,H., Fujimura,K., and Fujita,Y., (1989). Automatic Wiper Controller Using Optical Rain Sensor. Fujitsu Ten Technology Journal,2, pages 69-79.

[9] Kulkarni, T.S. \& Holand,H.S., ( July, 2012). Semi-Automatic Rain Wiper System, International Journal of Emerging Technology and Advanced Engineering (IJETAE), 2(7), 152-156 Retrieved on 19th January, 2016 from http://www.ijetae.com

[10] Madankar,S.B., \& Khanapurkar, M.M., (2011). Intelligent Rain Sensing using Automatic Wiper System, 2nd National Conference on Information and Communication Technology (NCICT) Proceedings Published in International Journal of Computer Applications (IJCA), 27-29

[11] Noor I.B.M.A. (2011). University of Technology, Malaysia. Automatic Windshield Wiper System, pages 6 $12,47,48$.

[12] Otte, E.A., Qaiser,A., Sandhu,I., Tazabekov,A., and Kang, D. (2010). Capacitive Sensor for Automatic Wiper Control, Hyundai-Kia American Technical Centre, Incorporation (HATCI), pages 2, 6-10.

[13] Viswanadh,K.V., Babu S.S., Krisha, J.L., \& Bahadur,A.L., (2015). Design \& Frabication of Rain Operated Wiper Mechanism using Conductive Sensor (IJERT), 4(1), 730-732. Retrieved on 15th January, 2016 from http://www.ijert.org 